\title{
Analysis of The Effect of Linear and Non-Linear Loads against The Quality of Power at The Power Converter
}

\author{
Anicetus Damar Aji ${ }^{1}$ and Kusnadi ${ }^{1}$
}

\begin{abstract}
Application of the linear and non-linear loads are widely used in household industries, office buildings and factories such as the power converters for motor speed control ac / dc. Un-interruptible power supplies (UPS). A fluorescent lamp with the electronic ballasts. If the use of linear and non-linear loads in power converters are based electronics will result in the power quality on electrical power distribution system will be worse. The power quality is affected by the value of the current or the voltage harmonics. The research in Electrical laboratory conducted to evaluate the power quality due the use of linear and non-linear loads in the form of the value of THD\% (Total Harmonic Distortion), the power factor and harmonic waves that arise in three-phase power converter and will be measurement by using the LAB-VIEW 8.5. The research are expected to result in variations of the value of the harmonics and power factor is a measure of power quality, to load in the form of linear likes lighting and non-linear loads such as motor loads or the other inductive loads.
\end{abstract}

Keywords—Linier Load, Non linier loads, Power Quality, LAB-VIEW 8.5.

\section{INTRODUCTION}

$\mathrm{O}$ the industrialization and Globalization now. The loads on electric distribution system are variation such as linier load likes resistive load combination inductive and capacitive loads or non linier loads as power electronics component base are use switching technique likes Uninterruptible Power Supply (UPS), Converter drive for AC and DC motor, Fluorescent lamp with electronic ballast and so on. Generally the non linier loads are inductive and will cause the current and voltage on the input side is distortion and the power quality of the system will be decrease [1].

There are the problems on the Power quality influences to the Power system. The one is the harmonics [2]. Harmonics cause by the use power converter equipment that will be voltage and current distortion make decrease of the power Quality.

Some problem on the power quality, the one is harmonics, harmonic caused by power converter are use on installs that will be cause the voltage and current distortion.

A harmonic of a wave is a component frequency of the signal that is an integer multiple of the fundamental frequency, i.e. if the fundamental frequency is $\mathrm{f}$ the harmonics have frequencies 2f. 3f. 4f. Etc. The harmonics have the property that they are all periodic at the fundamental frequency, therefore the sum of harmonics is also periodic at that frequency. Harmonic frequencies are equally spaced by the width of the fundamental frequency and can be found by repeatedly adding that frequency). Harmonics will cause the transformers fail and the support equipment, whereas his transformer function of two supplied power to the system and the other loads. Transformer will be temperature rises and makes decrease in efficiency. One of the major effects of power system harmonics is to increase the current in the system. This is particularly the case for the third harmonic, which causes a sharp increase in the zero

\footnotetext{
${ }^{1}$ Anicetus Damar Aji and Kusnadi are with Department of Electrical Engineering, Politeknik Negeri Jakarta, Depok, Indonesia. E-mail: adamaraji@yahoo.com; kusnadi1957@gmail.com.
}

sequence current. And therefore increases the current in the neutral conductor. This effect can require special consideration in the design of an electric

System to serve non-linear loads. The magnitude the distortion from the equipment calls Percentage Total Harmonic Distortion (THD \%). THD\% recommended by IEEE-Standard 1992 is $\leq 20 \%$.

The regulate of firing angle is important to operate controlled ac-c converter if it has inductive loads, if the firing angle inaccurate. The converter function is no stable. The converter will be good function if the THD on power quality is good. Power Quality Analyzer and Distortion Analyzer are some equipment to measure THD on the system. That equipment is the direct measure THD value.

On this research we use the newest method to measure THD by Lab VIEW 8.5 and NIDQ 6008, that can be automatically to gets the firing angle value. The THD on the input of the lines of ac-dc converter function of the firing angle if the variation inductive loads are applied.

\section{DESCRIPTION OF WORK}

The base research method is literate study by the plan design (software and hardware), simulation, realization and testing the system in the Power Electronic Laboratory . To measure the THD\% automatically at the converter input meshes on the inductive load work operations ignition angle. Description of the system is shown in Figure 1.

Measuring and monitoring THD\% value automatically to the input side of the ac-dc tree phase converter as the function of firing angle on the inductive loads will be displayed by computer.

Data aquisition we use the National Instrument product are compatible with the LabVIEW is DAQ6008. At the time of measurement will be display the value of THD response by the LabVIEW Program.

This reasearch use the current transformer to detection the input current of the line ac-dc converter. This research use the current transformer to measure the current of input line the ac-dc converter thats converted to the form of the input voltage at the NI-DAQ 6008 .The port data aquisition NIDAQ 6008 are Port Ai.0 use to input of line R ,Port Ao1 
are used as the voltage output IC TCA 785. the data will be send to the PC that will be display the block diagram of the measument data of THD\% automatically as figure 2 .

Set point THD value will be determine firing voltage value and be modified to firing angle can displayed .The current transformer use to be detect the current that change as voltage2 Volt for the input

DAQ ( Aio) and determine THD value is measure on the line of ac-dc converter and convert to be output voltage are 5 Volt as the output DAQ (Ao1) and will be determine by design of THD Set Point. Program design are figure.3.

The current transformer can supplies current and will be acquisition by NIDAQ 6008, the data will be uploaded on DAQ assistant on the software. The data's on DAQ Assistant will be displayed as THD response harmonic current wave and spectrum frequency. Spectrum frequency as harmonics values from the input line ac-dc converter uploaded the data's from the component on input line acdc converter, and the performance result the total harmonics.

The data's from DAQ Assistant changes to be Graph Indicator. On the Graph Indicator THD value will be displayed, there for the spectrum feculence. Data's from DAQ assistant as the input for Spectral Measurement and function block on waveform easement. To displayed Frequency Spectrum on the Spectral measurement selected the Peak Value, and on the spectral measurement on graph indicator will be displayed the value of spectrum Frequency on the Control as the fig. 4.

Control panel monitoring are:

a. Current Spectrum

b. THD\% Response

c. Distortion Current wave shape

d. THD set point

e. Error percentage

f. Tuning PID(Formula Quarter Decay Ratio)

With $K p=1.67$. $T i=0.0125$ and $T d=0.0001$ for analyze THD from $20 \%$ to $37 \%$. On the load L1= $0.25 \mathrm{H}$ and $\mathrm{L} 2=0.56 \mathrm{H}$.

\section{RESULT AND DISCUSSION}

\section{A. Converter Modulle ac-dc 220V/45V. 1500 Watt LeyBold}

For analyze the research of the automatic THD evaluate on the input side to the ac-dc converter three phase controlled consist of:

1. Measurement data's

2. View data's

3. And analyses data's to evaluate the THD function of fire angle to three phase controller converter to the variation inductive loads $\mathrm{L} 1=$ $0.25 \mathrm{H}$ and $\mathrm{L} 2=0.56 \mathrm{H}$

\section{B. Automatic THD Meter}

Current Transformer will detectc the current on the line ac-dc converter (Line R) will be modified to the voltage 2 Volt as the input DAQ, output DAQ 5 volt droped to the amplifier become 10 volt as the firing voltage (set circuit of the potensiometer 0 -10Volt) .

\section{Testing Procedures}

a. Build the configuration Observation as picture. 5

b. Regulate the value parameter of PID (Kc, Ti, and Td)

c. Determine the target THD

d. Set filename to storage measurement data

e. Run program

f. Observation the data firing angle, system response and error percentage

g. Stop Program

\section{Measurement Datas}

Measurement data firing voltage (0-10Volt) on control circuit of the three phase converter against THD on the input side of the line ac-dc converter for inductive loads $(\mathrm{L} 1=0.25 \mathrm{H}$ and $\mathrm{L} 2=0.56 \mathrm{H})$.

\section{E. $T H D=f(\propto$ dan $T H D=f(\% E)$}

From the average measures data for $\mathrm{L} 1=0.25 \mathrm{H}$ at the THDsp $=20 \%, 25 \%$, 30\%, 31\% , 33\%. 35\% and 36\%. And $\mathrm{L} 2=0.56 \mathrm{H}$ on the THDsp= 20\%,25\%,31\%,32\%,33\%,35\%, 36\% and 37\% available the graph shown in table 3 .

\section{F. Analisa Data}

For the optimal parameter firing angle and THD ac-dc converter that are :

1) The load $L 1=0.25 \mathrm{H}$

From The graphic 6.4 obtain THD\% value and \%E: value $31 \% \leq \mathrm{THD} \leq 35 \%$ and $52.2 \leq\left(\alpha^{0}\right) \leq 58.09$. With the represented error $\leq 0.2 \%$. For $\mathrm{THD}<31 \%$ will get the value of $\% \mathrm{E}>5 \%$. For $\mathrm{THD} \%>35 \%$ will get the value of $\% \mathrm{E}>4 \%$. From the control panel have the THD $<31 \%$ the response THD will be overshoot and unstable. THD $>35 \%$ response are stable without overshoot.

2) The Load L2 $=0.56 \mathrm{H}$

a. Fig. 7. has THD\% value and \%E: $31 \% \leq$ THD $\leq 36 \%$ and $\left(\alpha^{0}\right)=54$ at $\left(\alpha^{0}\right)$

b. From THD 31\% $-36 \%$ will be constant $=54$ degree with the error percentage $\leq 3 \%$

c. THD $<31 \%$ respond THD will be overshoot and unstable

d. THD>36\% respond is stable without overshoot. but $\%$ error $>31 \%$

e. The harmonic of current spectrum with the frequency $50 \mathrm{~Hz}, 250 \mathrm{~Hz}, 350 \mathrm{~Hz}, 550 \mathrm{~Hz}, 650 \mathrm{~Hz}$, $850 \mathrm{~Hz}$ and $950 \mathrm{~Hz}$

f. According Fourier series

$$
f(t)=a_{0}+\sum_{u=1}^{\infty}\left(a_{u} \operatorname{cosu} \omega t+b u \sin u n \omega t\right)
$$

g. $\mathrm{ao}=0$

h. $a n=0$ ( $n=$ odd and even)

i. $\quad b n=0(n=o d d)$

j. $\quad$ Amplitude $=6 \mathrm{I} / 4 \pi n$ (for $\mathrm{n}=$ odd)

k. From the input line current wave (iA) ac-dc converter available:

1. The operate $31 \% \leq \mathrm{THD} \leq 34 \%$. $\%$. Square harmonic current waveform symmetry (6 pulses)

m. The formula: $\mathrm{h}=\mathrm{kp} \pm 1$

n. Where $\mathrm{h}=$ Number of harmonic

o. $\mathrm{k}=$ Integer

p. $\mathrm{p}=$ pulse 
q. The current harmonic will be formulated:

r. $\mathrm{I}(\mathrm{t})=6 \mathrm{I} / 4 \pi$

$(\sin w t+1 / 5 \sin 5 w t+1 / 7 \sin 7 w t+1 / 11 \sin 11 w t+1 / 13 \sin$ $13 w t+1 / 17 \sin 17 w t+1 / 19 \sin 19 w t)$

$$
T H D=\frac{\sqrt{\sum_{h=2}^{h_{m a x}} I_{h}^{2}}}{I_{1}} \times 100 \% \ldots . . . . . .
$$

s. $\quad$ If I (t) will be: THD\% = 31\%. Formula 2.3 .

$$
\text { t. } P F=\frac{1}{\sqrt{1+\left[96 \frac{T H D}{100}\right]^{2}}} D P F
$$

u. If $\mathrm{DPF}=0$. Therefore $\mathrm{PF}=0.77 . \mathrm{DPF}=\operatorname{Cos} \Phi=0.9$ and $\mathrm{PF}=0.82$.

\section{CONCLUSION}

Based on the description and the discussion that has been presented previously. Authors formulate some conclusions as follows:

1. Operation of the three phase ac-dc converter controlled on Inductive load will result in distorted current waveform at the input side of the lines

2. THD\% (Total Harmonic Distortion) the three phase ac-dc converter controlled influences by the change of the firing angle and inductive load value.

3. The operation three phase ac-dc converter controlled will be cause THD measurement $31 \%$ with the spectrum frequency $250 \mathrm{~Hz}, 350 \mathrm{~Hz}, 550 \mathrm{~Hz}$ and $650 \mathrm{~Hz}$ with 6 symmetrical square waveform pulses.

4. On inductive load ( $\mathrm{L} 1=0.56 \mathrm{H})$ ac-dc converter should be operated at the $\alpha 0=54$ degrees with a value of $\leq 31 \%$ THD $\leq 36 \%$. output response will be stable and without overshooting with the percentage error $\leq 3 \%$
5. On inductive load ( $\mathrm{L} 1=0.25 \mathrm{H})$ ac-dc converter should be operated pad $52.2 \leq \alpha 0 \leq 58.09$ with the values of $31 \% \mathrm{THD} \leq 35 \%$. Output response will be stable. Without overshooting with the percentage error $\leq 0.2 \%$.

\section{ACKNOWLEDGEMENT}

Completing a Magister is truly a marathon event, and I would not have been able to complete this paper with the aid and support of my best friend. I must first express my gratitude towards my advisor, DR.Prawito. Her leadership, support, attention to detail, and hard work, have set an example I hope to match someday. Over the years. I'd like to thank the best friend in Jakarta Sate of Polytechnic. I wish to thanks Kusnadi, and I look forward to a continuing collaboration with you in the future. Finally, I thank to my parents for instilling in me confidence and a drive for pursuing my Magister.

\section{REFERENCES}

[1]. Mohan.Ned. (2003). Power Electronics And Drives http://www.MNPERE.com

[2]. Mohan. (1994). Power Eletctronic. Converter Applications and Design John Willey and Sons. Inc. Singapore.

[3]. National Instrument. (2009). DAQ 6008 Data Sheet.http://www.ni.com

[4]. Rashid.M.H. (1998). Power Electronics. Circuit. DevicesandAplications. Prentice -Hall International .Inc. New Jersey.

[5]. Rashid.M.H. (2010). Power Electronics Hand Book. AP.

[6]. Rashid.M. H. (2005) Digital Power Electronics \& Aplications. Elseiver Academic Press.USA.

[7]. Syafrudin. (1999).Perbaikan Faktor Daya Sistem Distribusi Tenaga Listrik yang mensuplai Beban Linier and Non Linier. Proceedings. Workshop and Seminar Power Electronics and Electrical Machinery. ITB.

[8]. Sharkawi.M. (2000). Fundamentals of Electric Drives Library of Congress Cataloging-in Publication Data. USA.2000

[9]. Tata (1990) Power Electronics McGraw-Hill Publishing Company Limited. New Delhi.

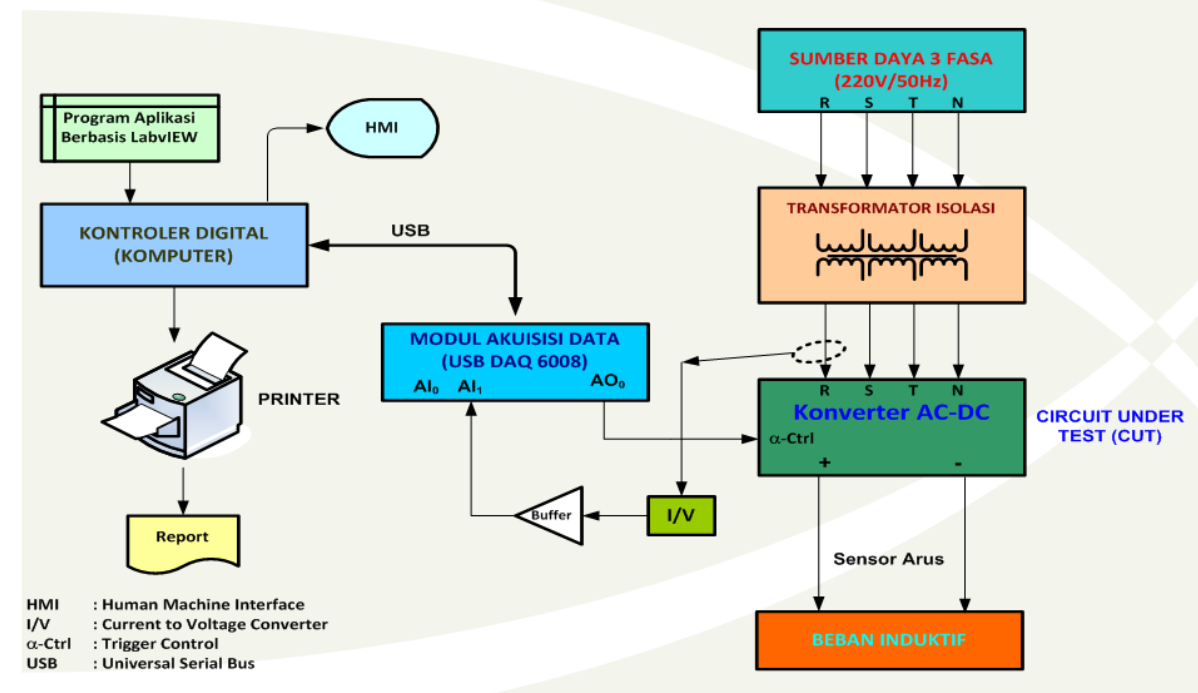

Figure 1. Description of the system 


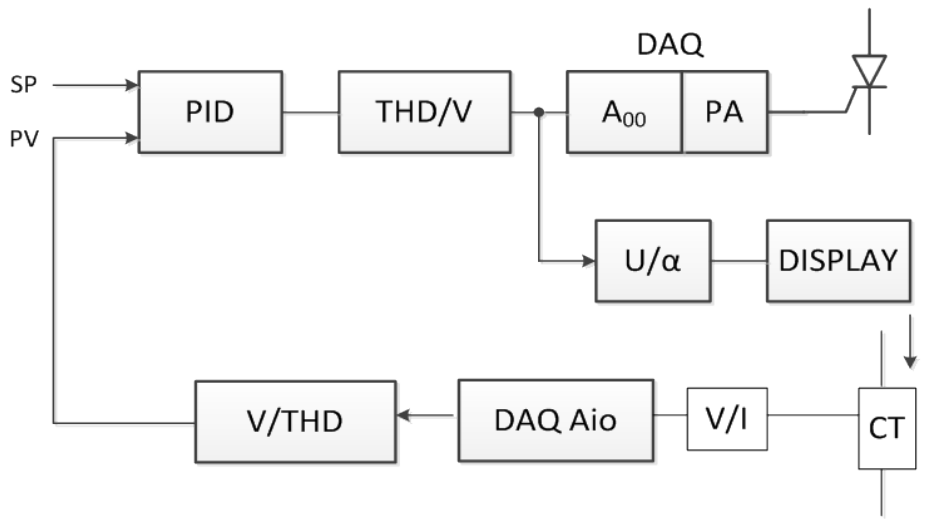

Figure 2. Automatically Block diagram THD Measurement

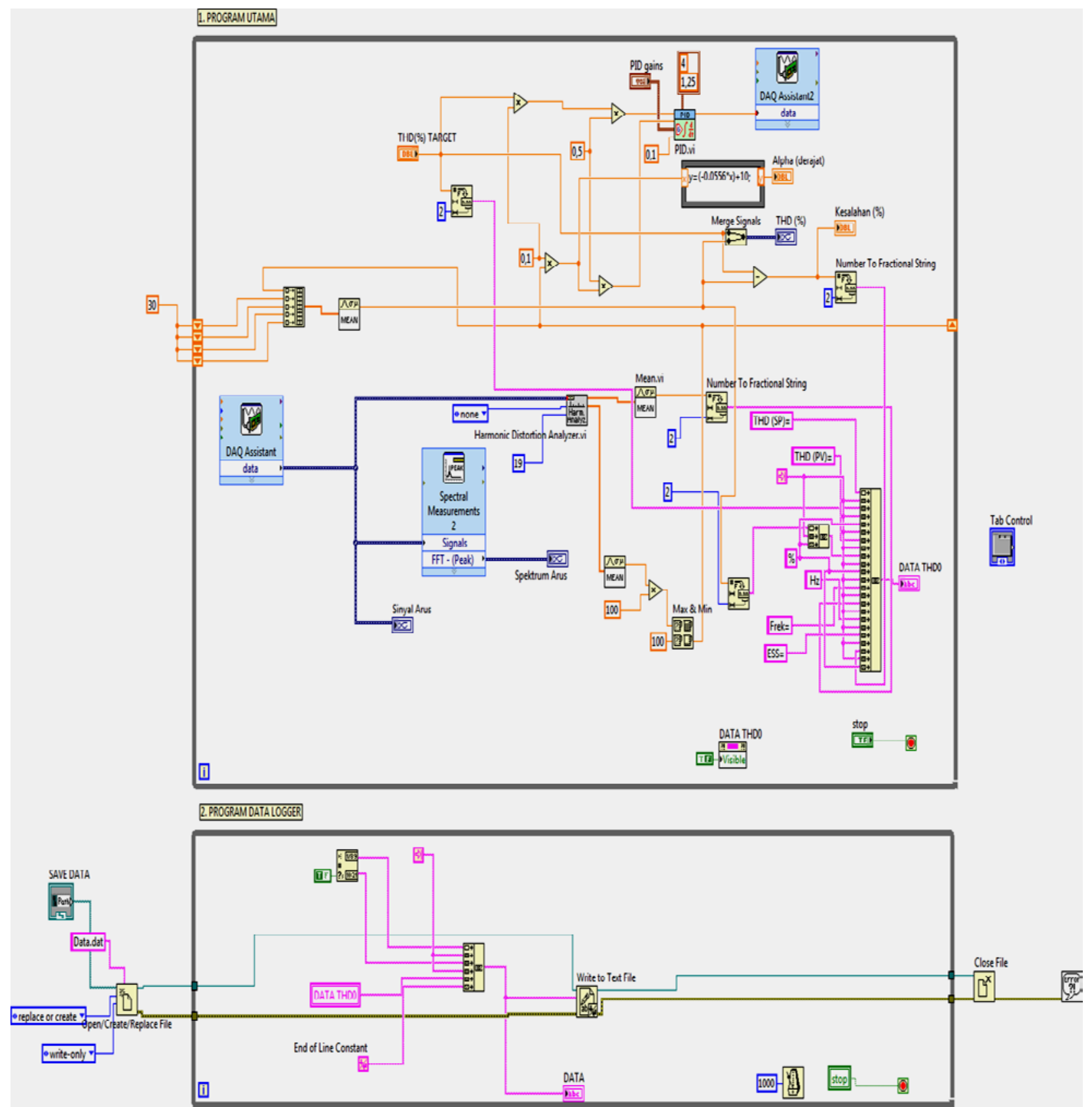

Figure. 3 Program Design 


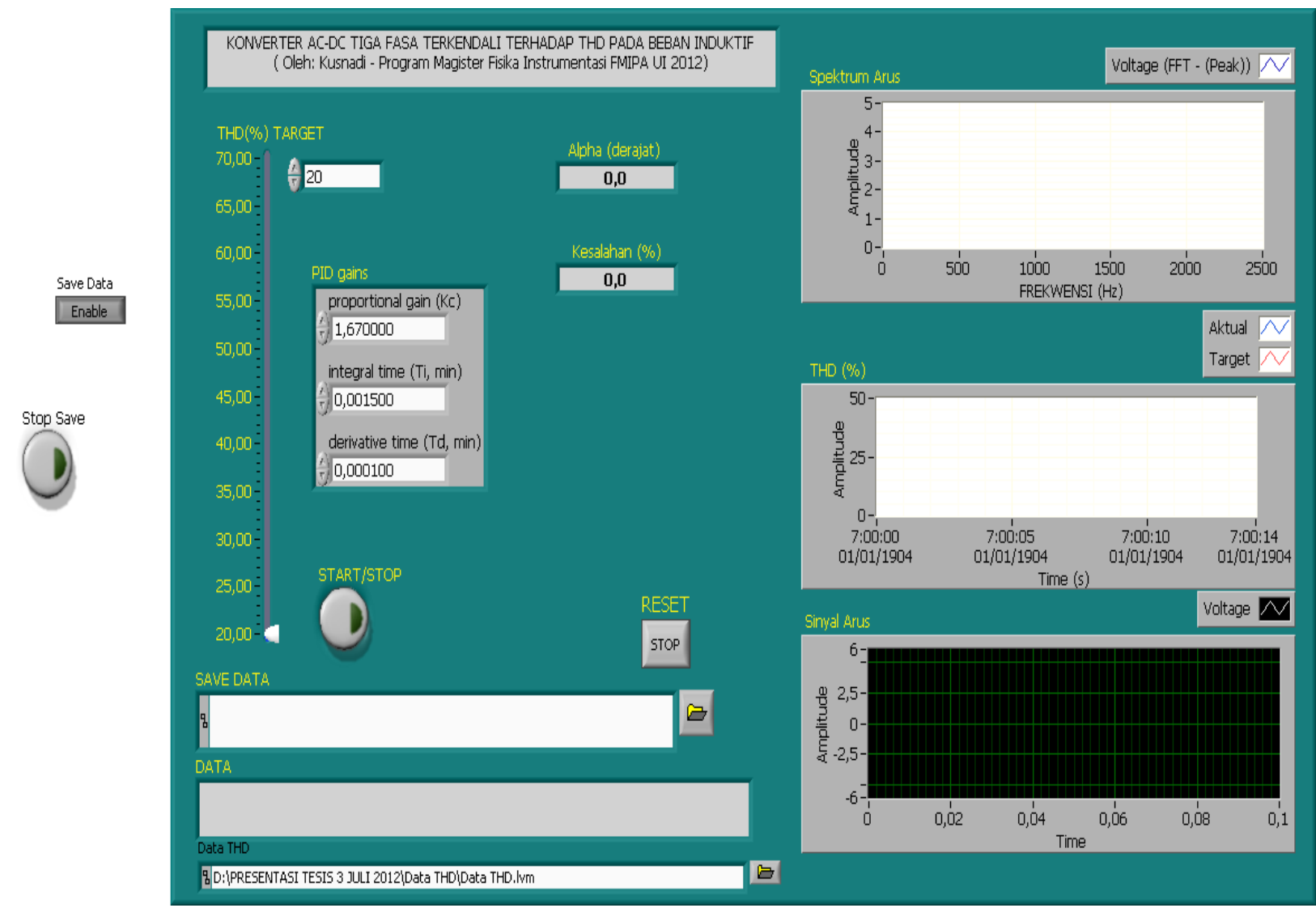

Figure 4. Control Panel

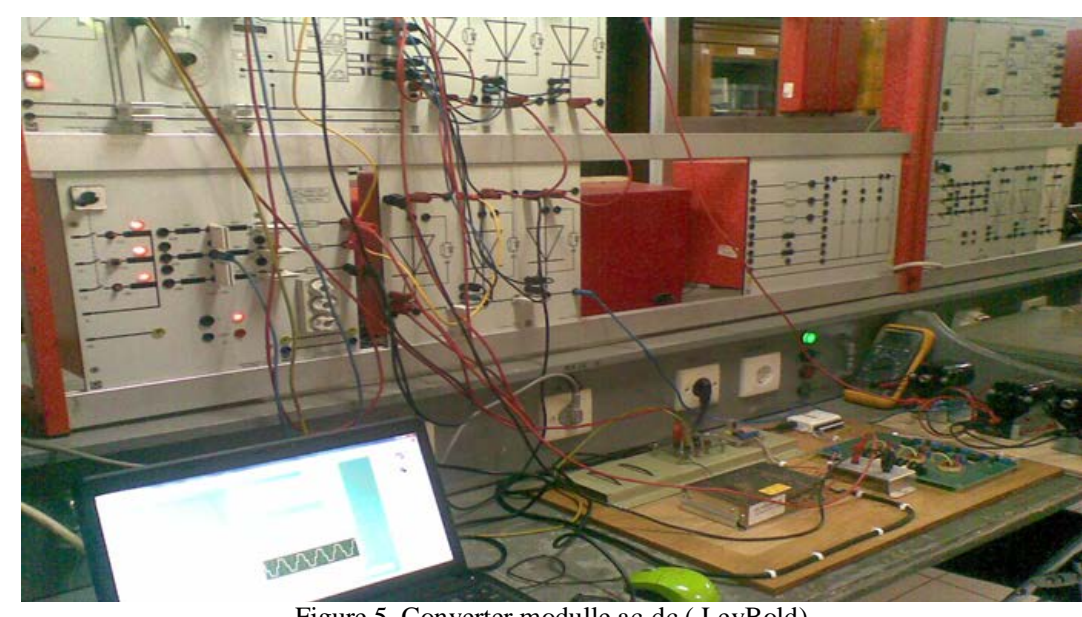

Figure 5. Converter modulle ac-dc ( LeyBold)

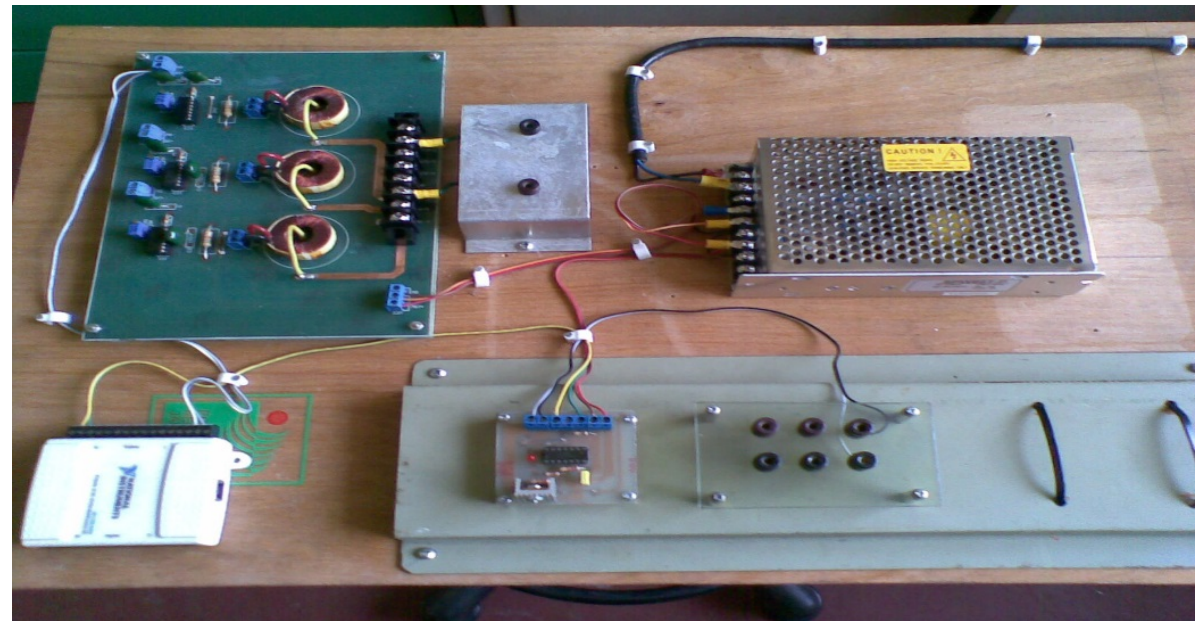

Figure 6. Automatic THD Meter 


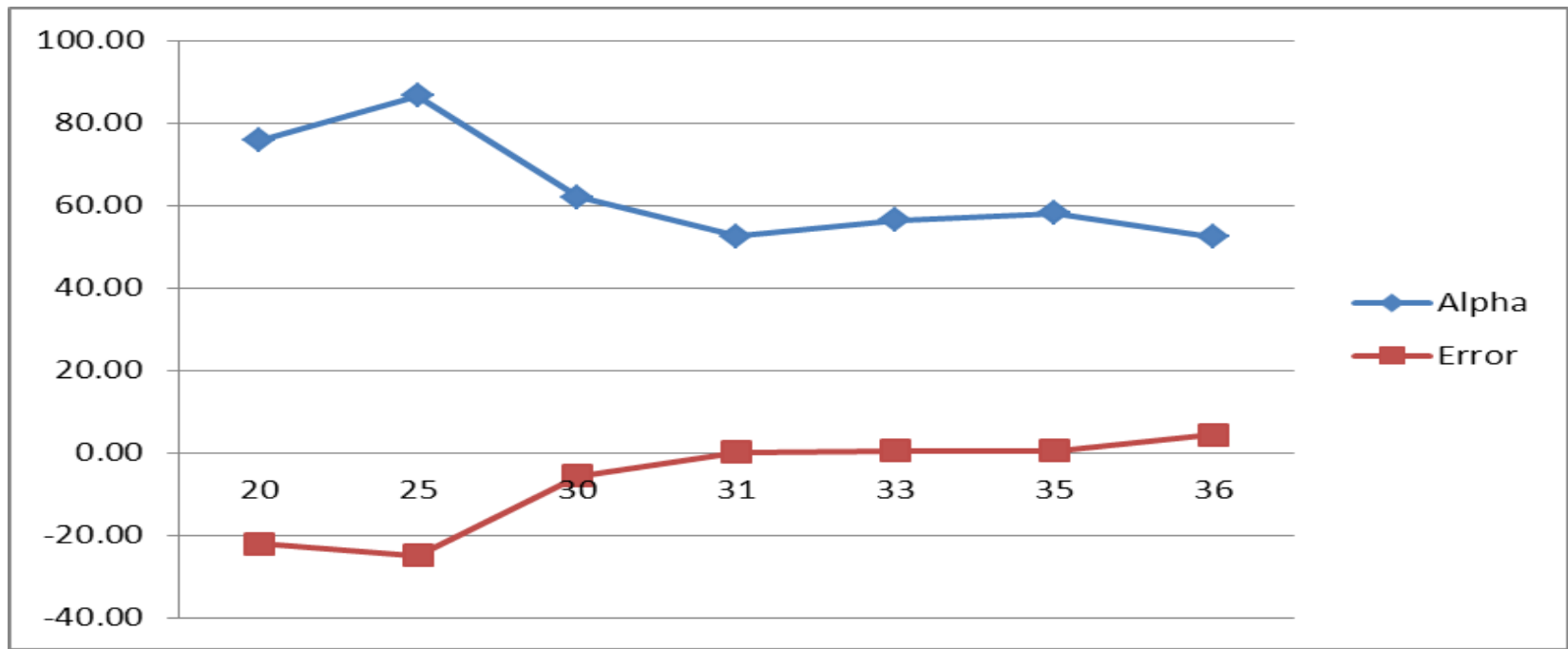

Figure 5.3 Graphic : $\alpha^{0}=\mathrm{f}(\mathrm{THD} \%)$. for $\mathrm{L} 1=0.25 \mathrm{H}$

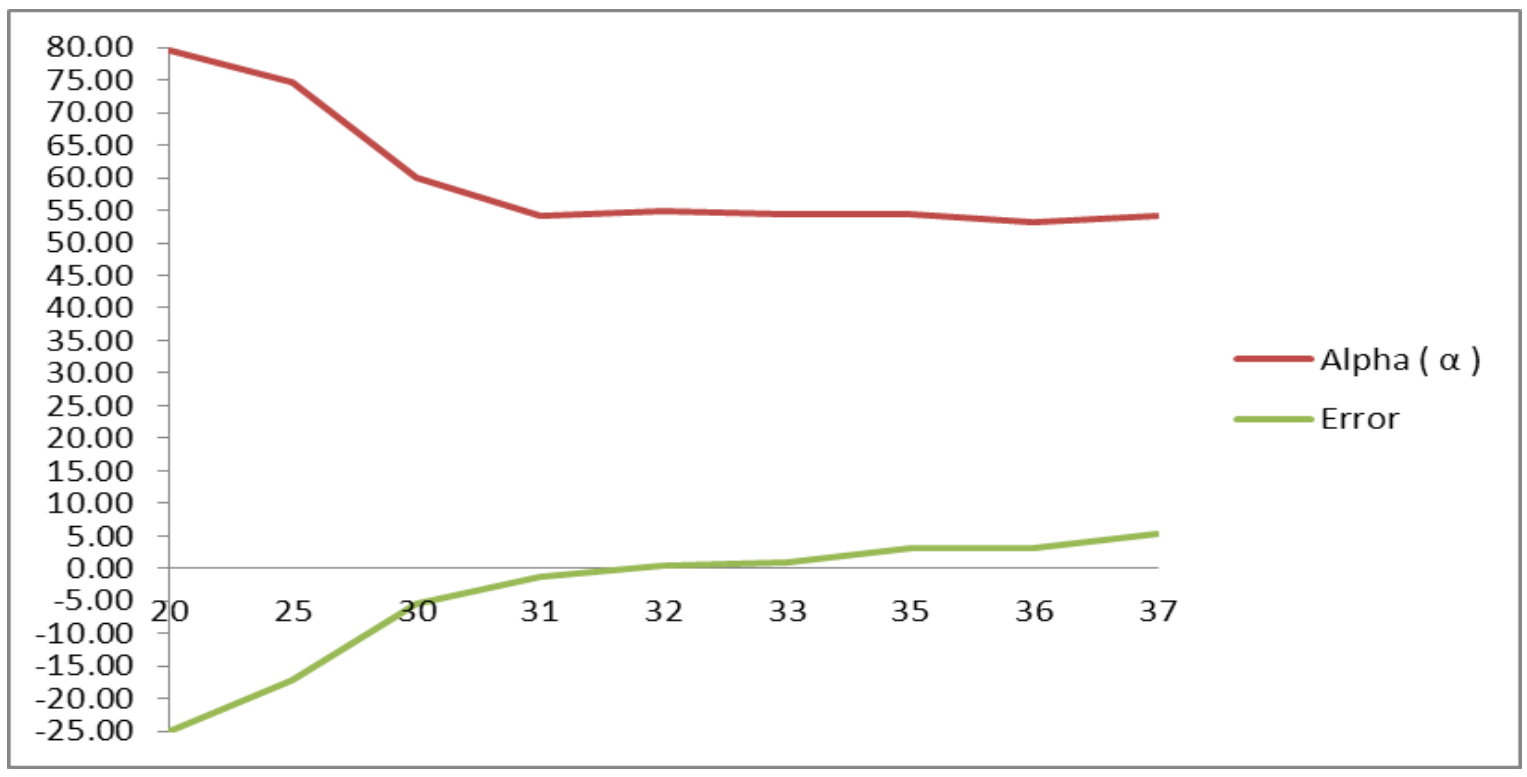

\%THD

Figure 7. Graphical : $\alpha^{0=}=\mathrm{f}(\mathrm{THD} \%)$, for $\mathrm{L} 2=0.56 \mathrm{H}$

TABLE 1.

VFIRING $=\mathrm{F}(\mathrm{THD})$

\begin{tabular}{cccccc}
\hline \hline No & $\begin{array}{c}\text { Vfiring } \\
(\mathbf{V})\end{array}$ & $\begin{array}{c}\text { THD } \\
(\%)\end{array}$ & $\mathbf{V}$ & $\begin{array}{c}\text { Freq } \\
(\mathbf{H z})\end{array}$ & Remarks \\
\hline 1 & 2.5 & 21.85 & 2.65 & 49.80 & $\mathrm{a}=0.940203$ \\
2 & 3.0 & 23.07 & 3.80 & 49.86 & $\mathrm{~b}=-17.895$ \\
3 & 3.5 & 23.39 & 4.10 & 50.12 & \\
4 & 4.0 & 23.46 & 4.16 & 50.29 & $\mathrm{~L} 1=0.25 \mathrm{H}$ \\
5 & 4.5 & 23.67 & 4.36 & 50.18 & \\
6 & 5.0 & 23.92 & 4.59 & 50.30 & \\
7 & 5.5 & 24.40 & 5.05 & 50.01 & \\
8 & 6.0 & 24.73 & 5.36 & 50.02 & \\
9 & 6.5 & 25.86 & 6.42 & 50.13 & \\
10 & 7.0 & 26.06 & 6.61 & 50.30 & \\
11 & 7.5 & 27.00 & 7.49 & 50.21 & \\
12 & 8.0 & 27.50 & 7.96 & 50.33 & \\
13 & 8.5 & 27.90 & 8.34 & 50.20 & \\
14 & 9.0 & 28.50 & 8.90 & 50.10 & \\
15 & 9.5 & 29.91 & 10.23 & 50.10 & \\
\hline \hline
\end{tabular}

TABLE 2.

VFIRING $=\mathrm{F}(\mathrm{THD})$

\begin{tabular}{cccccc}
\hline \hline No & $\begin{array}{c}\text { Vfiring } \\
(\mathbf{V})\end{array}$ & $\begin{array}{c}\text { THD } \\
(\mathbf{\%})\end{array}$ & $\mathbf{V}$ & Freq & Remarks \\
\hline 1 & 2.5 & 20.01 & 2.60 & 49.99 & $\mathrm{a}=1.095145$ \\
2 & 3.0 & 21.22 & 3.92 & 50.06 & $\mathrm{~b}=-19.3183$ \\
3 & 3.5 & 21.60 & 4.34 & 50.07 & \\
4 & 4.0 & 21.78 & 4.53 & 50.12 & $\mathrm{~L} 2=0.56 \mathrm{H}$ \\
5 & 4.5 & 21.80 & 4.56 & 50.21 & \\
6 & 5.0 & 21.90 & 4.67 & 50.23 & \\
7 & 5.5 & 22.30 & 5.10 & 50.02 & \\
8 & 6.0 & 22.71 & 5.55 & 49.94 & \\
9 & 6.5 & 23.43 & 6.34 & 50.24 & \\
10 & 7.0 & 23.60 & 6.53 & 50.27 & \\
11 & 7.5 & 23.77 & 6.71 & 50.11 & \\
12 & 8.0 & 24.12 & 7.10 & 50.61 & \\
13 & 8.5 & 24.99 & 8.05 & 50.14 & \\
14 & 9.0 & 26.33 & 9.52 & 50.04 & \\
15 & 9.5 & 27.22 & 10.49 & 50.01 & \\
\hline \hline
\end{tabular}


TABLE 3.

$\alpha=\mathrm{f}(\% \mathrm{THD})$ and $\alpha=\mathrm{f}(\% \mathrm{E})$ for $\mathrm{L} 1=0.25 \mathrm{H}$

\begin{tabular}{ccc}
\hline \hline THD & Alpha $(\boldsymbol{\alpha})$ & ESS \\
\hline 20 & 75.73 & -22.07 \\
25 & 86.50 & -24.86 \\
30 & 61.94 & -5.62 \\
31 & 52.52 & 0.20 \\
33 & 56.35 & 0.45 \\
35 & 58.09 & 0.46 \\
36 & 52.38 & 4.37 \\
\hline \hline
\end{tabular}

TABLE 4.

$\alpha=\mathrm{f}(\% \mathrm{THD})$ and $\alpha=\mathrm{f}(\% \mathrm{E})$ untuk $\mathrm{L} 1=0.56 \mathrm{H}$

\begin{tabular}{ccc}
\hline \hline THD & Alpha $(\boldsymbol{\alpha})$ & ESS \\
\hline 20 & 79.64 & -24.92 \\
25 & 74.68 & -17.18 \\
30 & 60.11 & -5.42 \\
31 & 54.13 & -1.17 \\
32 & 54.96 & 0.43 \\
33 & 54.37 & 1.02 \\
35 & 54.33 & 3.06 \\
36 & 53.17 & 3.07 \\
37 & 54.07 & 5.30 \\
\hline \hline
\end{tabular}

